
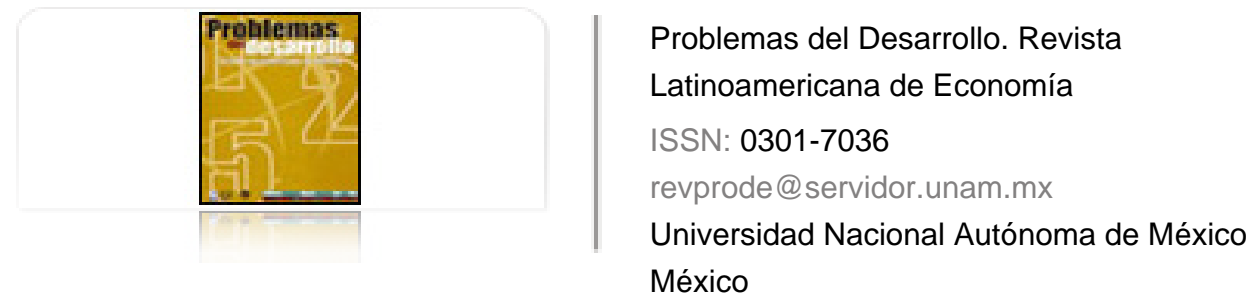

Casais Padilla, Enrique

La respuesta a la crisis en la UE: España camino de su "década perdida"

Problemas del Desarrollo. Revista Latinoamericana de Economía, vol. 42, núm. 166, julio-septiembre, 2011, pp. 37-62

Universidad Nacional Autónoma de México

Distrito Federal, México

Disponible en: http://www.redalyc.org/articulo.oa?id=11819777003

Cómo citar el artículo

- Número completo

- Más información del artículo

Página de la revista en redalyc.org

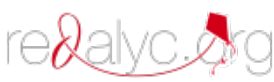

Sistema de Información Científica

Red de Revistas Científicas de América Latina, el Caribe, España y Portugal Proyecto académico sin fines de lucro, desarrollado bajo la iniciativa de acceso abierto 


\title{
LA RESPUESTA A LA CRISIS EN LA UE: ESPAÑA CAMINO DE SU “DÉCADA PERDIDA”
}

\author{
Enrique Casais Padilla*
}

Fecha de recepción: 9 de diciembre de 2010. Fecha de aceptación: 29 de abril de 2011.

"Quienes creen que el dinero lo hace todo, terminan haciendo todo por dinero"

Voltaire

\begin{abstract}
RESUMEN
Dentro del contexto actual de crisis global, las imposiciones del Banco Central Europeo (вСE) y el Fondo Monetario Internacional (FMI), principalmente en los aspectos relativos al control del déficit presupuestario y a la necesidad de nuevas reformas estructurales en el sistema público de pensiones y el mercado laboral, son una especie de "suicidio económico" para los países periféricos de la Unión Europea (UE), entre los que se encuentra España. Estas políticas van a condenar a España a un largo periodo de recesión y elevado desempleo, que nos invita a afirmar que, de no cambiar estas políticas, España va camino de su propia "década perdida".
\end{abstract}

Palabras clave: España, Unión Europea, crisis, déficit, BCE.

\section{THE RESPONSE TO THE CRISIS IN THE EU: SPAIN ON THE WAY TO ITS "LOST DECADE"}

\begin{abstract}
In the context of the present global crisis, the impositions of the European Central Bank (ЕСB) and the International Monetary Fund (IMF), mainly with respect to the control of the budget deficit and the need for new structural reforms in the public pension system and the labor market, are a species of "economic suicide" for the peripheral countries of the European Union (EU), among which is Spain. These policies will condemn Spain to a long period of recession and high unemployment, which leads us to affirm that, if these policies not changed, Spain will experience its own "Lost Decade".
\end{abstract}

Key words: Spain, European Union, crisis, deficit, ЕСв.

* Investigador del Departamento Economía Aplicada I de la Universidad Complutense de Madrid. Correo electrónico: le.casais@ccee.ucm.es 


\section{LA RÉPONSE À LA CRISE DANS L'UE : L'ESPAGNE SUR LE CHEMIN DE SA « DÉCENNIE PERDUE »}

\section{Résumé}

Dans le contexte actuel de crise mondiale, les diktats de la Banque centrale européenne (BCE) et du Fonds monétaire international (FMI), principalement dans les aspects relatifs au contrôle du déficit budgétaire et au besoin de nouvelles réformes structurelles dans le système public de retraites et le marché du travail, sont une espèce de « suicide économique " pour les pays périphériques de l'Union européenne (UE), entre lesquels se trouve l'Espagne. Ces politiques vont condamner l'Espagne à une longue période de récession et de fort taux de chômage, qui nous pousse à affirmer que, faute de changer ces politiques, l'Espagne est sur le chemin de sa propre "décennie perdue ».

Mots clés : Espagne, Union européenne, crise, déficit, ВСE.

\section{A RESPOSTA À CRISE NA UE: ESPANHA A CAMINHO DA SUA «DÉCADA PERDIDA» Resumo}

Dentro do contexto atual de crise global, as imposiçóes do Banco Central Europeu (BCE) e do Fundo Monetário Internacional (FMI), principalmente nos aspectos relativos ao controle do déficit orçamentário e da necessidade de novas reformas estruturais no sistema público de pensóes e do mercado laboral, são uma espécie de "suicídio econômico" para os países periféricos da Uniāo Européia (EU), entre os quais se encontra a Espanha. Essas políticas vão condenar a Espanha a um longo período de recessão e elevado desemprego, que nos convida a afirmar que, de não se alterar estas políticas, o país vai a caminho da sua própria "Década Perdida".

Palavras-chave: Espanha, Uniāo Européia, crise, déficit, вCE.

\section{对欧洲危机的回答：西班牙，走在他的迷失期 \\ 小结}

在当今全球危机的大环境下, 欧洲中央银行（BEC）和世界货币组织（FMI） 的税收, 主要是对预算逆差的控制, 以及对社会公共福利和劳动力市场的 体系在结构改革的需要上的税收, 对于欧盟 (UE) 的边缘国家来说是一 种“经济性质的自杀”，这些边缘国家中就包括了西班牙。这些政策将会 使西班牙进入一个长期的经济衰退和高失业率时期, 并且我们敢肯定, 如 果这些政策不改变的话, 西班牙将走在它的“迷失期”。

关键词：西班牙, 欧盟, 危机, 逆差, 欧洲中央银行 


\section{INTRODUCCIÓN}

Se ha escrito mucho sobre los orígenes y las causas de la crisis financiera en los países desarrollados. Éste no es el objeto de este artículo. Sin embargo, se pueden subrayar tres puntos que han facilitado el desarrollo de las burbujas especulativas y sus estallidos:

- La desregulación financiera en Estados Unidos, que permite asumir mayores riesgos y niveles de apalancamiento sin precedentes a la Banca Comercial y de Inversión. Y a su vez, vender de manera muy lucrativa los riesgos tomados por los bancos, gracias a la concepción y emisión de productos financieros bajo la forma de títulos negociables cada vez más sofisticados.

- La evaluación de estos riesgos por las agencias de rating no fue todo lo diligente que se esperaba de ellas. En los últimos años pasaron de calificar como AAA (máxima calificación) a unas pocas decenas de esos activos hasta varios miles antes del estallido de la crisis.

- La adopción de reglas contables que permiten valorizar los activos a partir de sus precios de mercado (market to market).

Para retomar una expresión de Minsky, "Una característica fundamental de nuestra economía es que el sistema financiero oscila entre la robustez y la fragilidad, y esa oscilación es parte integrante del proceso que genera los ciclos económicos" (...) "se llega muy rápidamente a un financiamiento de tipo Ponzi y la inestabilidad se impone sobre el conjunto del sistema financiero" (Minsky, 1986: 15$){ }^{1}$

La falta de confianza y la necesidad de "abandonar el barco" antes de que éste se hunda desencadena una brutal falta de liquidez en el mercado. Los bancos cesan de prestarse entre ellos y, por extensión, frenan brutalmente sus préstamos a las empresas. El credit crunch transforma la crisis financiera en una crisis

1 Minsky murió en 1996, un año antes que comenzara a cumplirse su pronóstico con la crisis asiática, hoy considerada un breve prolegómeno de la crisis actual. Uno de sus principales aportes teóricos fue su Hipótesis de la inestabilidad inherente, fundamentada en la fragilidad de los mercados financieros. Según él, los periodos largos de estabilidad económica llevan a los inversionistas a asumir riesgos en forma creciente y a los bancos y empresas a apalancarse en forma excesiva. Minsky advirtió que en tiempos de prosperidad se desarrolla una euforia especulativa que hace aumentar el volumen de crédito hasta que los beneficios producidos no pueden pagarlo. Y este momento del impago es el que desata la crisis. El resultado es una contracción del préstamo, incluso para aquellas empresas o personas que sí pueden pagarlo, momento en que la economía entra en colapso. 
económica. De esta manera, la crisis se vuelve sistémica. La falta de liquidez afecta a todos; incluso a las empresas que tuvieron una gestión prudente, lejana de la manipulación lucrativa de productos financieros titulizados.

En ese contexto, los Estados fueron la solución. El Estado español, al igual que la mayoría de los Estados desarrollados del mundo, acudió al rescate de la economía inyectando enormes sumas de dinero público con el objetivo de estimular la demanda, estabilizar el sistema financiero, suavizar la intensidad de la recesión, mitigar sus efectos sociales y acortar, en lo posible, la duración del fenómeno. De esta manera se evitó una gran recesión en el corto plazo, pero los problemas estructurales de España han continuado agravándose con el desarrollo y la evolución de la crisis.

A partir de la primavera de 2010, la presión de los mercados internacionales de bonos ejercida sobre los endeudados países periféricos de la Eurozona, han provocado la necesidad de que el Banco Central Europeo (вСE) y el Fondo Monetario Internacional (FMI) hayan acudido al "rescate" financiero de Grecia, Irlanda y Portugal, hasta la fecha.

En este contexto, las políticas adoptadas para salir de la actual crisis impuestas por el BCE y el FMI, apoyadas por los países centrales de la Unión Europea (UE), se basan en la profundización de las políticas neoliberales anteriores a la crisis: políticas de austeridad fiscal y nuevas reformas estructurales en los mercados laborales y los sistemas públicos de pensiones. ${ }^{2}$

2 Para un análisis amplio de las "recomendaciones" del BCE respecto a las necesidades de nuevas reformas estructurales en España se puede consultar el Boletín de marzo 2010 del Banco Central Europeo (вСE) (previo a las reformas aprobadas por el gobierno espańol en junio 2010) donde expresamente dice: "Con el fin de garantizar el mantenimiento de la confianza en la sostenibilidad fiscal y de evitar efectos de contagio negativos en otros países miembros y en la uEm en su conjunto, es fundamental que los países de la zona del euro cumplan íntegramente los compromisos adquiridos en el contexto de los procedimientos de déficit excesivo. En particular, los esfuerzos de saneamiento tendrán que ser ambiciosos en muchos países, y sustentarse en medidas estructurales creíbles y especificadas claramente, centrándose especialmente en la reforma del gasto", p. 91 y continúa "La actualización del programa de estabilidad de España prevé la corrección del déficit excesivo del país para 2013, en consonancia con las recomendaciones formuladas en el contexto del procedimiento de déficit excesivo. El objetivo de saneamiento estructural medio anual establecido es de 1.8 puntos porcentuales del PIB, acorde con la recomendación formulada en el marco del procedimiento de déficit excesivo de lograr un ajuste superior a 1.5 puntos porcentuales. No obstante, este objetivo no se ha visto plenamente respaldado por medidas concretas, especialmente para el periodo 2011 2013”, p. 96. A partir de este informe, el debate sobre la necesidad de reformas estructurales se generalizó en los medios de comunicación, y su resultado fue el Real Decreto-Ley 8/2010, de 20 de mayo, por el que se adoptan medidas extraordinarias para la reducción del déficit público, Boletín Oficial del Estado (BOE), 2010. 
La hipótesis a desarrollar es que estas políticas de corte neoliberal van a condenar a estos países periféricos de la UE, entre los que se encuentra España, a un largo periodo de recesión, elevadas tasas de desempleo y el desmantelamiento de sus débiles Estados del bienestar. Esta recreación de una estructura centroperiferia en el seno de la UE va a ser altamente negativa para los países meridionales que posiblemente se encuentren ya inmersos dentro de su propia "Década Perdida". ${ }^{3}$

Hay que hacer constar que este breve apunte no agota un análisis completo de la situación contradictoria actual que están viviendo España y la UE. No obstante, sí puede servir de orientación para enfocar los principales lugares de conflicto.

\section{EL MODELO DE DESARROLLO ESPAÑOL: “"MILAGRO ECONÓMICO” O "ESPEJISMO”?}

Para el caso español, son varias las causas de la crisis que está padeciendo. En primer lugar, el modelo de desarrollo español. Éste fue calificado como "milagro económico" y modelo a copiar para muchos países en desarrollo. No obstante, se trataba de un modelo altamente contradictorio, que generó grandes distorsiones en la economía.

Durante el periodo se dio un constreńimiento acusado de las rentas salariales frente a las ganancias del capital, mientras se generaba una enorme burbuja inmobiliaria (y en menor medida, otra bursátil) debido a las liberalizaciones financiera y del suelo. La magnitud de estas distorsiones invita a afirmar que, aun sin haber existido una gran crisis global, el modelo de desarrollo español tenía muy escasas posibilidades de haberse mantenido viable en el largo plazo. ${ }^{4}$

El modelo de crecimiento español alcanzó grandes logros económicos en términos de crecimiento y acercamiento a los niveles de renta de las principales

3 El concepto "Década Perdida" es ampliamente utilizado para referirse a la grave situación de crisis que sacudió a la región latinoamericana en la década de los 80 del siglo pasado. En este estudio se opina que la asunción de recetas neoliberales para hacer frente a los problemas actuales pueden realmente provocar una situación parecida a los países meridionales de la eurozona.

4 Los países periféricos de la UE con problemas tienen un denominador común: en los años anteriores a la crisis, la demanda interna se mantuvo gracias al crédito externo. Las tasas cada vez más elevadas de deuda privada, financiada por la banca de los países centrales, se tornaron insostenibles con el corte de estos flujos a partir del año 2007. 
potencias capitalistas antes del estallido de la crisis. Si en 1980 el nivel del PIB per cápita español representaba un 59\% del PIB per cápita de la UE-I 5 , sólo 25 años después las diferencias se habían recortado hasta suponer un $80 \%$ del mismo (Eurostat, 2010).

Hasta 2007, la estrategia española era muy valorada internacionalmente, motivo por el cual muchas economías - especialmente latinoamericanas- se veían reflejadas en la España de hace unas décadas, con el objetivo de mimetizar una senda similar de progreso.

La apertura de la economía española se realizó, principalmente, mediante la integración de España en la UE. Durante estos años, la economía española se ve sometida a un profundo proceso de transformación estructural materializado en la aplicación de sucesivas reformas en diferentes dimensiones. Para cumplir con las exigencias de los futuros socios europeos y poder acceder a la entonces Comunidad Económica Europea, España debió acometer una importante reconversión industrial durante la década de los 80 del siglo pasado. Ya entrados en los 90, destacaríamos las reformas estructurales en los ámbitos laboral, financiero e inmobiliario, por ser las más relevantes y causa directa de la crisis actual.

\section{Las reformas laborales}

Desde que en 1980 se aprobara el Estatuto de los Trabajadores, España ha realizado más reformas laborales que ningún otro país europeo, en total 9 hasta 2010. Tres de ellas han configurado el actual modelo laboral, y las tres fueron realizadas sin consenso con los sindicatos. Su autoría es la responsable del modelo laboral actual: precario, volátil, dual, con alto porcentaje de bajos salarios y corresponsable de la baja productividad. ${ }^{5}$

La reforma de 1984 se instauró aduciendo a la rigidez del mercado de trabajo que, se argüía, explicaba las altísimas tasas de paro españolas. Bajo el lema de "más vale un trabajo precario que ninguno", se aprobó la contratación temporal sin causa y la finalización del contrato con una mínima indemnización. La temporalidad pasó a cronificarse y afectar a un tercio del mercado de trabajo.

La reforma de 1994 consistió, en sus líneas generales, en una flexibilización del despido y el aumento de la discrecionalidad empresarial. Estos factores

5 Para una información exhaustiva y detallada de las 9 reformas laborales acaecidas desde 1980, se puede consultar el siguiente documento, usado como referencia. http://www.ccoo.cat/pdf_documents/REFORMAS\%20\%20LABORALES.pdf 
deberían corregir la temporalidad en la contratación, consecuencia principal de la anterior reforma. La principal consecuencia del incremento de la arbitrariedad empresarial fue debilitar la negociación colectiva y la disminución de los salarios. El grado de temporalidad no disminuyó.

La reforma de 2002, con parecidos argumentos, convirtió en superfluo el recurso a la tutela judicial en el despido improcedente y redujo, mediante la eliminación de los salarios de tramitación, los costes del mismo. Esa reforma sumó a la altísima temporalidad acarreada una penetración suplementaria de la inestabilidad laboral en el universo de los contratos indefinidos, al crecer de manera exponencial los despidos objetivos improcedentes.

Como se ha dicho, estas tres reformas han marcado la realidad del mercado laboral español. En el caso de la reforma del año 2010, su "justificación” tiene origen en la actual crisis global que está afectando sobremanera a España en términos de destrucción de empleos y el problema de la dualidad entre trabajadores temporales y fijos. ${ }^{6}$

Esta última reforma laboral, una vez más, no da respuesta a los problemas fundamentales de la economía española. Se centra en un drástico abaratamiento del despido y en hacerlo más automático, en el debilitamiento de la negociación colectiva y en el reconocimiento de las agencias privadas de colocación. Esta reforma cierra el bucle de las anteriores y generaliza la inestabilidad. Pero no consigue, al igual de las anteriores, generar más empleo de calidad que realmente reactive el mercado de trabajo; la gran asignatura pendiente en España.

Una amalgama de intereses empresariales, de apriorismos ideológicos, de diagnósticos sesgados, de argumentos económicamente poco fundados, ha sido la principal causa de esta obsesión por la reducción del precio del despido y del coste del trabajo en las sucesivas reformas. Esto ha alimentado, a su vez, una cultura empresarial centrada en el ajuste del factor trabajo y no en la flexibilidad interna pactada, la innovación y la productividad.

No es creíble que con la generalización de la inestabilidad vaya a aumentar la productividad. En diciembre de 2006, la productividad media por trabajador en España era de 63075 dólares, lo que sitúa en un diferencial de unos doce

6 El 19 de septiembre de 2010 entró en vigor la Reforma Laboral (Ley 35/2010). Se trata de una Reforma Laboral "en dos fases". Primero el Gobierno aprobó una reforma del mercado de trabajo mediante un Real Decreto-Ley (RD-Ley 10/2010 de 16 de junio de 2010) que entró en vigor al mismo tiempo que se iniciaba su tramitación parlamentaria como proyecto de ley. Boletín Oficial del Estado (вов) Real Decreto-Ley 10/2010, de 16 de junio, de medidas urgentes para la reforma del mercado de trabajo. 
puntos respecto a la UE-I 5 y de 30 puntos respecto a la media norteamericana (70.7\%), pero teniendo en cuenta que el número de horas trabajadas anualmente en España (1 775) es más alto que en la UE-I 5 (1 611), la diferencia aumenta hasta más de 40 puntos porcentuales (80.3\% europeo frente a un $38.4 \%$ español) (Moreno, Molina y Luque, 2010: 3-5).

El Cuadro 1 muestra la productividad media por empleado en diferentes países de la UE-27, y EeUU. En él se ve claramente cómo la reforma laboral del año 2002 no consiguió el objetivo declarado de aumentar la productividad por empleado en España. Esto puede justificarse por el gran aumento del mercado laboral experimentado en estos años previos a la crisis. El problema del mercado laboral español es que cuando la economía va bien el resto de países de la zona euro suelen tener aumentos de productividad superiores a los españoles. El empleo creado en las épocas de bonanza en nuestro país suele estar asociado a trabajos de menos valor añadido y menos especialización.

Y, consecuencia lógica de lo anterior, durante la crisis, los trabajadores despedidos tienen mayor dificultad para adquirir los conocimientos, la experiencia y el aprendizaje necesarios para aportar un importante valor ańadido en su empresa. Mientras, sus equivalentes alemanes o ingleses, que han visto a sus empresas adoptar medidas de flexibilidad laboral sin llegar a despedirles, han podido utilizar los momentos de vacas flacas para formarse.

Es muy difícil que una empresa se gaste dinero en formar a un trabajador temporal, aun en tiempos de bonanza, ya que siempre se espera que esa persona será la primera en salir despedida ante cualquier adversidad; y tampoco es fácil que se haga fijo a alguien si manteniendo su situación de temporalidad, la empresa vive "más tranquila" ya que el coste del despido -si las cosas se tuercen o su rendimiento no es el esperado- es significativamente menor.

Unido a los intentos fallidos de las reformas laborales, hay que destacar que las políticas del BCE, que impusieron una tasa de interés uniforme para una región con tasas de inflación diferentes, no ayudaron a un país como España. La tasa de inflación española más elevada que la de nuestros principales socios de la UE-I 5 , representó una tasa de interés real menor que incidió sobre el endeudamiento. Funcionó, además, como un virtual retraso cambiario que afectó la competitividad industrial y estimuló la sobre expansión de los servicios, en especial financieros e inmobiliarios.

De la conjunción de estos factores se desencadena el importante déficit comercial español que no consigue verse compensado con las caídas de los costos laborales. Si a esta situación le añadimos la disponibilidad de amplias líneas de créditos baratos para una fracción del sector privado, principalmente el sector inmobiliario donde se concentra una parte sustancial del endeudamiento, 
Cuadro 1. Productividad laboral por persona empleada (EU-27=100, PPS)

\begin{tabular}{lrrrrrr}
\hline & 2002 & 2003 & 2004 & 2005 & 2006 & 2007 \\
\hline Eu-27 & 100.0 & 100.0 & 100.0 & 100.0 & 100.0 & 100.0 \\
Euro Área & & & 110.3 & 110.6 & 110.2 & 110.2 \\
Estados Unidos & 138.0 & 139.8 & 140.8 & 143.2 & 142.8 & 142.7 \\
Bélgica * $^{*}$ & 136.6 & 134.8 & 132.2 & 132.0 & 131.3 & 130.2 \\
Bulgaria $_{\text {República Checa }}$ & 33.1 & 33.5 & 33.8 & 34.3 & 34.8 & 35.7 \\
Dinamarca & 63.1 & 66.7 & 68.1 & 68.9 & 70.4 & 73.6 \\
Alemania & 108.6 & 106.4 & 108.8 & 109.2 & 108.3 & 106.0 \\
Estonia & 106.5 & 108.8 & 108.3 & 107.4 & 106.9 & 105.7 \\
Irlanda & 49.3 & 53.0 & 55.3 & 59.0 & 61.7 & 64.7 \\
Grecia & 133.5 & 135.5 & 134.8 & 133.8 & 134.7 & 135.7 \\
España & 100.5 & 100.3 & 101.8 & 103.5 & 103.8 & 105.0 \\
Francia * & 105.0 & 104.0 & 102.2 & 102.0 & 102.9 & 105.1 \\
Italia & 125.7 & 121.8 & 120.8 & 123.7 & 124.0 & 124.3 \\
Luxemburgo & 117.8 & 115.7 & 112.3 & 111.1 & 108.9 & 108.0 \\
Países Bajos & 163.5 & 166.8 & 169.8 & 175.6 & 183.9 & 180.3 \\
Austria & 113.4 & 111.0 & 112.4 & 115.3 & 114.4 & 114.3 \\
Portugal & 118.0 & 118.8 & 119.0 & 119.9 & 119.8 & 119.9 \\
Finlandia & 68.0 & 68.5 & 67.2 & 68.6 & 68.5 & 69.9 \\
Suecia & 111.6 & 109.6 & 112.8 & 110.8 & 112.3 & 111.9 \\
Reino Unido & 107.8 & 110.2 & 113.5 & 112.9 & 113.8 & 115.3 \\
Noruega & 110.3 & 110.6 & 112.3 & 109.7 & 109.5 & 108.8 \\
Suiza & 131.7 & 135.2 & 142.6 & 155.3 & 158.9 & 154.7 \\
\hline & 107.5 & 105.7 & 105.2 & 105.2 & 105.8 & 108.9 \\
\hline
\end{tabular}

Fuente: Elaboración propia con datos de Eurostat (tsieb030 y tsieb040), OCDE.

* Corresponde a una ruptura en la serie de medición en 2004.

se entiende la deriva productiva del modelo español hacia la construcción y el sector servicios.

Óscar Ugarteche, entre otros académicos, encuentra parecidos entre este cuadro español anterior a la actual crisis con el que padeció la región latinoamericana en la década de los 80 del pasado siglo. Para el profesor Ugarteche, este modelo contradictorio transformó el milagro espańol en un modelo explosivo. ${ }^{7}$

Para una mayor y exhaustiva comprensión de las similitudes entre la crisis en España y Latinoamérica se pueden consultar, entre otras, la siguiente página web, con algunos trabajos del profesor Ugarteche: http://www.rebelion.org/mostrar.php?tipo=5\&id=Oscar\%20 Ugarteche\&inicio $=0$ 
Curiosamente, la productividad está aumentando en España desde los orígenes de la crisis en 2007. En principio, un aumento de la productividad siempre debería ser motivo de alegría. Sin embargo, como explica con claridad el profesor Esteve, la subida de la productividad por persona ocupada "se ha derivado de la inexistencia generalizada de planes de reducción de jornada laboral y del mayor ajuste relativo de las plantillas de las empresas" . ${ }^{8}$ Las compañías alemanas, francesas o inglesas han visto bajar su productividad a cambio de apretarse el cinturón sin despedir a sus trabajadores (con medidas de reducción de jornada, congelación de los salarios o pactos con sus empleados). Mientras, en España, la tendencia general ha sido deshacerse de los empleados sin contrato fijo, debido a la mayor proporción de contratos temporales en nuestro país (Esteve, 2010: 2).

Como ejemplo, en España en enero de 2011 se registraron en el Instituto Nacional de Empleo (INEM) un total de 1116019 contratos. De ellos, el 9.2\%, es decir, 102733 contratos, fueron de carácter indefinido. Los contratos temporales sumaron 1002982 y 10304 fueron contratos formativos. El 29.45\% de los contratos temporales fueron eventuales por circunstancias de la producción y el $29.41 \%$ eran de obra o servicio.?

A esta situación hay que añadir que España es el cuarto país del mundo donde más horas se trabajan al año y el primero de Europa. Los trabajadores españoles trabajan una media de 1775 horas al año (ocDE, 2010).

Cuadro 2. Horas trabajadas anuales

\begin{tabular}{ccccccccccc}
\hline \multicolumn{1}{c}{ Año 2009} & $\begin{array}{c}\text { Corea } \\
\text { del Sur }\end{array}$ & $\begin{array}{c}\text { Estados } \\
\text { Unidos }\end{array}$ & Japón & España & Francia & $\begin{array}{c}\text { Reino } \\
\text { Unido }\end{array}$ & Suecia & Italia & Alemania & $\begin{array}{c}\text { Países } \\
\text { Bajos }\end{array}$ \\
\hline $\begin{array}{l}\text { Horas trabajadas } \\
\text { al año }\end{array}$ & 2165 & 1785 & 1784 & 1775 & 1620 & 1607 & 1601 & 1566 & 1432 & 1413 \\
\hline
\end{tabular}

Fuente: Elaboración propia con datos de OCDE, 2010.

El grave desempleo es otro problema sucinto al alto número de horas trabajadas. Cuanto menos se reparten las horas de trabajo "disponibles" en la economía

8 Vicente Esteve es catedrático de Economía en la Universidad de Valencia, España, y autor de numerosas obras sobre productividad y mercados laborales. "Viaje al fondo de las finanzas internacionales", Blogspot, 2010: 2.

9 Ministerio de Trabajo e Inmigración. Estadísticas, disponible en http://www.mtin.es/es/estadisticas/index.htm 
entre los trabajadores y los posibles trabajadores, menos individuos podrán acceder al mercado laboral.

Entre 2002 y 2006, el salario medio español se alejó de la media europea, ya que la remuneración promedio en la UE-27 tuvo un incremento real del 3.9\% y la española sólo de un $1.3 \%$. Es el único país que, estando por debajo de la media, no se aproximó a la misma. ${ }^{10}$ Mientras que los costes laborales aumentaron durante el periodo 1999-2004 sólo un 3.7\%, los beneficios empresariales aumentaron un 73\% (Navarro, 2010a).

Contrariamente a lo esperado, este proceso de desvalorización de las rentas salariales no provocó un serio problema de demanda interna, ya que ésta fue estimulada mediante un intenso proceso de endeudamiento de las familias. Otro problema asociado a la disminución de los salarios se encuentra en la disminución de las cotizaciones a la seguridad social, al estar ésta alimentada exclusivamente por las rentas salariales. En este caso, el espectacular incremento del número de cotizantes en el mercado laboral español de las últimas décadas fue suficiente para garantizar la solvencia de las cuentas de la seguridad social.

El Cuadro 3 muestra la evolución de los cotizantes con empleo a la seguridad social. En él se ve que el aumento espectacular de cotizantes ha compensado las disminuciones de cotizaciones por empleado durante el periodo. Mientras en diciembre de 1988 el sistema de seguridad social tenía casi 12 millones de cotizantes, en julio de 2007 -mes récord de cotizantes en la historia de España- la cifra era de casi 19 millones y medio. Un incremento espectacular y sin precedentes en menos de 20 ańos. No obstante, este boom ha sido revertido en estos años de crisis y en enero de 2011 el sistema de seguridad social español contaba con 2,1 millones menos de cotizantes respecto al máximo reseñado.

Cuadro 3. Evolución cotizantes con empleo a la Seguridad Social en España

\begin{tabular}{ccccc}
\hline & Diciembre 1988 & Diciembre 2000 & Julio 2007 & Enero 2011 \\
\hline Número de cotizantes & 11776913 & 15236218 & 19493051 & 17361468 \\
\hline
\end{tabular}

Fuente: Elaboración propia con datos del Ministerio de Trabajo e Inmigración.

10 Para el año 2008, el salario medio anual bruto en la UE-25 era de 32414 euros. Sin embargo, dicha media esconde una gran disparidad, ya que en países como Dinamarca, Reino Unido o Alemania, la remuneración promedio supera los $40000 €$ anuales, mientras que en los países del Este no superan los $10000 €$. En España, el salario medio anual bruto en ese mismo año era de $21402 €$. 
La Organización Internacional del Trabajo (оIт) ${ }^{11}$ especifica que son 30 millones los nuevos parados en el mundo desde que se manifestó la crisis, de los cuales España ha aportado casi el 10\%. El desempleo en los últimos años ha aumentado desde un $8.5 \%$ en 2005 a casi el $21 \%$ en septiembre de 2010 , y las previsiones oficiales estiman que no baje del 15.5\% a finales del año 2013 .

Unido a la constricción salarial, la reforma inmobiliaria y la liberalización del suelo, permitieron que grandes flujos de capitales, provenientes principalmente de la banca alemana y francesa, encontraran acomodo y grandes beneficios especulando en territorio español, de manera que se fue gestando otro aspecto muy relevante del "milagro español"; la generación de una enorme burbuja inmobiliaria que explotó en 2007.

\section{La burbuja inmobiliaria}

El sector inmobiliario experimentó un ciclo muy dinámico desde la segunda mitad de los noventa hasta el principio del dos mil, fechas muy recientes en numerosos países, destacando Estados Unidos, Reino Unido y España, lo que se reflejó en incrementos notables en los precios de la vivienda y en un creciente protagonismo del sector de la construcción en la economía. Esta fase de auge de los mercados residenciales ha venido seguida de otra de declive, en la que los precios y la actividad han retrocedido.

Entre 1998 y 2006 el intenso dinamismo registrado en los mercados de la vivienda de Estados Unidos, Reino Unido y España, se tradujo en crecimientos interanuales de los precios significativos, superiores en muchos casos al $10 \%$ interanual, en términos reales, fase que ha venido seguida de una notable corrección posterior, en contraste, con otras economías -como Alemania o Japón- donde no se produjo este ciclo alcista (Marqués, Maza y Rubio, 2010: 108).

La adquisición de un inmueble residencial, como en el mercado de cualquier bien de consumo, el precio y la cantidad dependen de factores de oferta y demanda. Entre las variables relevantes de demanda de vivienda se encuentran, principalmente, las tendencias demográficas, el tamaño de los hogares, los flujos migratorios, el ritmo de crecimiento económico, la creación de empleo y la fiscalidad. En cuanto a la oferta, se encuentra condicionada por factores tales como el coste de los inputs utilizados en la construcción, el grado de

11 orT. Informe sobre el Trabajo en el Mundo 2010: ¿De una crisis a la siguiente?, 2010. 
competencia entre las empresas constructoras o la legislación existente para crear suelo residencial. ${ }^{12}$

Además, existen otros factores de naturaleza financiera que también influyen en la evolución del mercado residencial. Tanto la adquisición como la construcción de una vivienda suelen realizarse de forma muy apalancada, es decir, son adquiridas o construidas con una pequeña aportación de recursos del comprador o constructor, siendo el resto financiado por una entidad de crédito. Por ello, las condiciones y modalidades que existen para financiar una vivienda y los criterios en la concesión de las hipotecas tienen un impacto significativo tanto en la oferta como en la demanda de activos residenciales.

En los últimos años, la capacidad de financiación de las entidades de crédito hacia este sector se vio notablemente incrementada por el desarrollo de los mercados internacionales de titulización y otros productos (como, por ejemplo, las cédulas hipotecarias u otras formas de bonos garantizados -Covered Bonds-), lo que permitió que las entidades crediticias dispusieran de mayores posibilidades para expandir sus balances, incluso en algunos casos de regulación poco estricta, sin la necesidad, en ocasiones, de incrementar su capital en la misma proporción. En el caso de España, estos fenómenos se conjugaron con el proceso de incorporación a la Unión Económica y Monetaria, que supuso un impulso adicional a la capacidad de endeudamiento de los agentes, al contribuir a un entorno macroeconómico más estable y a una mayor integración financiera internacional.

Hay que destacar que muchas de estas variables tienen una naturaleza estructural y presentan escasas variaciones en el tiempo, por lo que es difícil cuantificar sus efectos empíricamente. Así, no es sencillo medir la importancia que pudieron tener el nivel de competencia, el grado de especialización y la regulación del sistema financiero en la expansión inmobiliaria de España. No obstante, sí se puede afirmar que una característica del supuesto "milagro de crecimiento económico y creación de empleo" español fue la enorme inversión bancaria en el sector inmobiliario, creándose el complejo banca-sector inmobiliario-industria de la construcción, que fue el motor de tal supuesto milagro. Como consecuencia de ello, el sector construcción llegó a representar el 12\% del PIB, más del doble de lo que tal sector representaba en Francia (Navarro, 2010c).

La desregulación del precio del suelo llevada a cabo en esos años, es un elemento clave para entender cómo pudo crecer de ese modo el sector inmobiliario

12 En el caso español, muchos académicos opinan que el punto de inflexión en la burbuja inmobiliaria española fue el Real Decreto Ley 4/2000, 23 de junio de 2000, con el que se pretende liberalizar el mercado del suelo en España. Para una explicación exhaustiva de dicho Real Decreto se puede consultar en: http://noticias.juridicas.com/base_datos/Admin/rdl4-2000.html 
en España y provocar dicha burbuja. Entre los años 2000 y 2007 el porcentaje destinado por los hogares españoles a la vivienda pasó del $12.40 \%$ al $25.63 \%$ del gasto total. En cifras absolutas, significa pasar de gastarse unos $80000 \mathrm{mi}-$ llones de euros en vivienda al año a más de 200000 millones (Navarro, 2010a).

Para calcular el impacto negativo que la explosión de la burbuja inmobiliaria ha provocado en España, a pesar de las dificultades ya expuestas, no es suficiente con medir el impacto de tal explosión en la producción, es decir, en el 12\% del PIB ocupado por el sector antes de la crisis, sino que hay que incluir también su impacto en el consumo. Los propietarios de las viviendas se veían más ricos de lo que eran, y por ello aumentaron su consumo. ${ }^{13}$

Cuando la burbuja estalló, resultado en gran parte de la negativa de las bancas alemanas y francesas a continuar prestando liquidez a los bancos españoles, éstos tuvieron una enorme cantidad de viviendas vacías sin posible comprador. Aún más, con la evolución de la crisis, la situación de muchas familias en España se ha tornado crítica y los bancos se encuentran en un proceso de ejecuciones hipotecarias sin precedente. Según el Consejo General del Poder Judicial, durante los años 2007 a 2009 se firmaron unas 178000 ejecuciones hipotecarias frente a las 47379 del trienio anterior. ${ }^{14} \mathrm{Si}$ a estos datos le sumamos las estimaciones de diversos medios que afirman que al finalizar el año 2010 habría que añadir otras 180000 más, nos encontraremos con que el total de ejecuciones hipotecarias en los últimos cuatro años ascenderá a más de 350 000. Más que en los últimos 20 años juntos (Diario Cinco Días, 24/7/2010).

Lamentablemente, parece que esta situación se va a mantener bastante tiempo en España. Si el mercado funcionara correctamente, una manera de que la banca pudiera vender las viviendas vacías y reavivar así el mercado inmobiliario podría ser bajando los precios. La banca, sin embargo, no lo está haciendo. En realidad el precio de la vivienda ha bajado sólo un $12.8 \%$ desde el momento en que había alcanzado el mayor precio en el año 2006 (Navarro, 2010c). ${ }^{15}$

13 En eevu se ha calculado que de cada dólar que sube el valor de la propiedad, el propietario aumenta su consumo 5 céntimos. Ello implica un incremento del consumo de $500000 \mathrm{mi}-$ llones de dólares para la economía estadounidense (Navarro, 2010c). La falta de estudios solventes sobre el caso español, no debe hacernos olvidar este componente que seguro se ha visto afectado por la burbuja inmobiliaria.

14 Consejo General del Poder Judicial, Informe anual 2010.

15 La mayoría de expertos inmobiliarios en países europeos calcula que el precio de las viviendas en España debiera bajar un $30 \%$ o un $40 \%$ para que funcionara de nuevo el mercado de la vivienda y se recuperara así la economía. The New York Times, "Newly Built Ghost Towns Haunt Banks in Spain” (18/12/10). Disponible en http://www.nytimes.com/2010/12/18/ world/europe/18spain.html?_r=4\&ref=global-home 
La banca prefiere mantener viviendas vacías esperando a que pueda venderlas más tarde a unos precios artificialmente altos. No obstante, desde hace meses, esta situación se está tornando peligrosa, pues las agencias de valoración de la deuda privada no creen que la banca española haya absorbido los costes de su enorme comportamiento especulativo. De ahí que tengan sus dudas sobre la estabilidad y fortaleza de la banca española. ${ }^{16}$

En conclusión, el colapso de la burbuja inmobiliaria ha provocado el enorme problema de la falta de crédito en España, mientras que la reducción de la masa salarial ha creado el enorme problema de endeudamiento privado y la escasa demanda interna. En la conjunción de estos fenómenos se encuentra la clave fundamental para entender el proceso de parálisis y crisis que vive la economía española actualmente.

\section{LAS POLÍTICAS ECONÓMICAS DEL BCE: ¿ESPAÑA CAMINO DE SU “DÉCADA PERDIDA”?}

Para evitar una nueva "Gran Depresión”, la mayoría de los países aumentaron en mayor o menor medida su déficit público, socializando de esta manera las pérdidas de la burbuja financiera. Una de las claves para entender los procesos derivados de esta actuación prácticamente universal, radica en las diferentes maneras en que cada Estado ha afrontado posteriormente su déficit. Los países con soberanía monetaria la han utilizado ampliamente para monetizar el déficit y financiar la política fiscal expansiva, a la vez que para garantizar la deuda y estabilizar su valor en los mercados financieros. Por el contrario, los países de la ue sin soberanía monetaria se han enfrentado al déficit con el único instrumento de la deuda pública, que en consecuencia ha debido crecer aún más, mientras el BCE se limitaba a recomendar planes de austeridad fiscal y abandonaba a su suerte a los países en dificultades. ${ }^{17}$

16 El 24 de noviembre de 2010, el NY Times publicaba un artículo en el que desconfiaba claramente sobre la información aportada por la banca espańola y el Banco de España titulado "A Spanish Bailout Would Test Europe's Strained Finances”, disponible en http://www.nytimes. com/2010/11/25/business/global/25spainecon.html?pagewanted $=1$

17 Para un mayor entendimiento sobre las posiciones del вCE respecto a los déficits fiscales y a la necesidad de nuevas reformas estructurales, se puede consultar el boletín trimestral del вСE de marzo de 2010. Asimismo, los principales diarios, la televisión y la radio estuvieron permanentemente comunicando la necesidad de nuevas reformas como la "solución" a la crisis. 
En un momento especialmente crítico de la historia económica contemporánea, los países de la zona euro con dificultades financieras derivadas de la crisis han descubierto una amarga verdad: la máquina de hacer billetes nunca más será utilizada para combinar la política monetaria y la política fiscal. La creación del всE, como un organismo supranacional al margen de los Estados, se ha convertido en un golpe de Estado financiero al apropiarse de la política monetaria de la UE.

La política de la disciplina fiscal, de la reducción del déficit, la deuda, el tamaño del gobierno y del sector público, que nos gobernó antes de la crisis, se esgrime ahora como programa para salir de ella. Se trata, en definitiva, de reducir el Estado de bienestar, recortar los derechos laborales, debilitar a los sindicatos, reducir los salarios y aumentar la explotación para, en definitiva, incrementar los beneficios de las clases empresariales.

Estas actuaciones condenarán a la recesión y al estancamiento a los países periféricos de la eurozona como Grecia, España, Portugal, Irlanda, los países bálticos y posiblemente algún otro. La Unión Europea, asistida por el FMI y dominada principalmente por la banca alemana, lleva ańos aplicando estas políticas en los países bálticos como condición para ser admitidos en la eurozona. Los resultados han sido desastrosos. El pів de estos países se ha reducido en promedio casi un $20 \%$ desde que tales reformas se iniciaron en 2007. Ningún país desde que eEuU perdió el 25\% de su PIB durante la Gran Depresión ha experimentado una situación semejante. Como ejemplo, en diciembre de 2008 el FMI proyectaba que la economía de Letonia sufriría una contracción del 5\% en 2009. En la realidad, el resultado fue una contracción del 18\%. En un caso menos extremo, Irlanda comenzó a reducir su déficit fiscal a finales de 2008. En ese entonces, el FMI pronosticaba un crecimiento del $1 \%$ para 2009; el resultado final fue de menos 10\% (FMI, 2010).

El FMI, no obstante, asume con excesivo optimismo y falta de realismo que tales economías se recuperarán. Pero incluso en sus proyecciones reconocen que en Lituania el PIB será en 2014 un 7.1\% menor que el del año 2007; en Estonia un $9.1 \%$; y en Letonia un 14\%. Al mismo tiempo, en todos ellos el desempleo se ha disparado y se encuentra actualmente entre el 15\% y el 20\% (Eurostat, 2010).

Los países latinoamericanos, con gobiernos de "izquierdas", que se han atrevido a expulsar al FMI, llevan ańos gozando de crecimiento y mejor salud que cuando eran "aconsejados" por esta institución. Argentina, con el gobierno Kirchner en 2001, cambió radicalmente sus políticas económicas, abandonando las políticas neoliberales del FMI, y en lugar del desastre que el FMI había vaticinado, después de seis meses desde el inicio de políticas keynesianas, creció un $9 \%$ durante los siguientes seis años. Una situación semejante ocurrió en Bolivia, 
donde el gobierno Morales cambió radicalmente de políticas. Aplicó políticas expansivas de gasto público, nacionalizando a la vez el gas y el petróleo. Bolivia es hoy uno de los países con mayor crecimiento en América Latina.

En definitiva, seguir las políticas "recomendadas" por el FMI es profundamente erróneo. En pleno 2011 creer que el estímulo económico provendrá del aumento de la competitividad para aumentar las exportaciones es cuando menos, ingenuo. La recuperación económica de Alemania se está usando para sostener la idea de que los alemanes habrían dado con la fórmula adecuada; hacer sacrificios a corto plazo para obtener el éxito a largo plazo. Esta fórmula, se dice, pasa por adoptar las políticas de austeridad que ahora tienen que implantar los países periféricos de la UE. Desde luego que Alemania ha hecho algunas cosas bien, pero su fórmula no ha incluido el tipo de políticas pro-cíclicas y sacrificios sociales que el BCE y el FMI están exigiendo a España. El déficit presupuestario alemán en el primer semestre de 2010 se multiplicó por dos en relación con el año 2009 para situarse en el 3.5\% del PIB. Es cierto que aún es más bajo que el de muchos otros países europeos, pero la realidad es que los alemanes no están recortando su déficit presupuestario, como en cambio están obligando a hacer a España.

Si a esta situación añadimos que nuestra productividad es menor que la alemana, la única posibilidad de competir para los países como Espańa se basa en seguir con las devaluaciones internas que fueron el motor de los ańos del "milagro económico". Lo que ocurre es que los salarios españoles ya están "por los suelos", y al contener Alemania también sus costes salariales reinicia una espiral descendente que nos lleva a todos al abismo (Weisbrot, 2010: 4-5).

A efectos prácticos, de seguir Alemania con esta estrategia, la conclusión es que ni Espańa, ni la periferia de la UE, pueden pertenecer a la eurozona. Los problemas de una moneda común entre países con diferentes niveles de productividad tendrá que afrontarlos la eurozona tarde o temprano.

\section{LAS CONSECUENCIAS EN ESPAÑA: REFORMAS Y FINANCIACIÓN CADA VEZ MÁS CARA}

Desde la primavera de 2010, España, junto a otros países periféricos de la eurozona, se ha convertido en el foco de los problemas en torno a la deuda soberana en Europa. Los diferenciales a pagar por las renovaciones de deuda se encuentran en máximos. Los costos de la financiación española han aumentado considerablemente y la calificación sobre sus bonos soberanos ha sido reducida por las, hasta hace muy poco, desprestigiadas agencias de calificación de riesgo. 
Como respuesta a la presión de los mercados financieros, y para cumplir con los requisitos para obtener asistencia si fuera necesaria, del вCE y del FMI, el gobierno implementó en el verano de 2010 un plan de austeridad que incluye recortes en el gasto público por 15300 millones de euros, o cerca del $1.4 \%$ del PIB, durante los próximos dos años. El gobierno también pretende aumentar la recaudación fiscal en 17900 millones de euros, o cerca del 1.6\% del PIB, para un ajuste fiscal total de cerca de $2.9 \%$ рів. Estos recortes presupuestarios e incrementos en los impuestos españoles pretenden estabilizar la relación deuda bruta/Рів a un nivel del 69\% del рів para el año 2013, con un nivel de endeudamiento neto de $62.4 \%$ (Boletín Oficial del Estado (вов), 2010)..$^{18}$

El Cuadro 4 resulta muy ilustrativo respecto a las posiciones de "los mercados". Antes de la crisis griega, España pagaba por su deuda soberana unos tipos de interés a corto plazo que rondaban el $0.60 \%$, a medio plazo el $2 \%$ y a largo plazo alrededor del 4\%. Entonces, el fmi y el вCE, en vez de monetizar los déficits de los países que pudieran tener problemas a corto plazo, aprueban un fondo de garantía de 750000 millones de euros y "recomiendan" a España que acometa un severo plan de ajuste, con el objetivo declarado de "calmar a los mercados". Desde ese momento, se dispararon los diferenciales a pagar por la deuda soberana en España y otros países.

18 Boletín Oficial del Estado. воE. "Real Decreto-Ley 8/2010, de 20 de mayo, por el que se adoptan medidas extraordinarias para la reducción del déficit público. Las medidas más importantes son:

Se rebajará de media un 5\% el sueldo de los funcionarios y quedará congelado a partir de 2011. De cualquier modo la reducción del salario será proporcional a su magnitud, afectando más a los sueldos más altos. En lo que se refiere a los miembros del gobierno, el salario se rebajará en un $15 \%$.

Se suprimirá a partir del $1^{0}$ de enero de 2011 el "cheque bebé" de 2500 euros por cada nacimiento, del que se beneficiaban las familias indistintamente de los ingresos que tuvieran.

Las pensiones no se revalorizarán el año que viene a excepción de las pensiones mínimas y las no contributivas.

Sólo los mayores de 61 años que tengan al menos 30 años cotizados y seis años de antigüedad en su puesto de trabajo podrán beneficiarse de la jubilación transitoria.

Se elimina la retroactividad de la ley de dependencia y las solicitudes deberán resolverse como máximo en seis meses. Así, no se cobrarán las cantidades pendientes acumuladas desde que se hiciera la petición.

La ayuda oficial al desarrollo se recortará en 600 millones de euros.

Las Comunidades Autónomas y las entidades locales deberán recortar el gasto en 1200 millones de euros.

Se recortará la inversión pública estatal en 6045 millones de euros en 2010 y 2011.

Se reducirá el gasto sanitario a través de la adecuación de las dosis de medicamentos fraccionando las dosis de los envases. 
Cuadro 4. Tipos de interés pagados por la deuda soberana española 2010

\begin{tabular}{|c|c|c|c|c|c|}
\hline & $\begin{array}{l}\text { Tipos I } \\
\text { interés } 6 \\
2009\end{array}$ & $\begin{array}{l}\text { ios de } \\
\text { marzo } \\
\text { il } 2010\end{array}$ & $\begin{array}{l}\text { Después del Plan del } \\
\text { FMI / BCE de } 750.000 \\
\text { millones de } €\end{array}$ & $\begin{array}{l}\text { Subasta } \\
23 / 11\end{array}$ & $\begin{array}{l}\text { Incremento en porcentaje } \\
\text { sobre la media de los } 12 \\
\text { meses anteriores) }\end{array}$ \\
\hline \multirow{2}{*}{$\begin{array}{l}\text { Letras } \\
\text { del } \\
\text { Tesoro }\end{array}$} & tres meses & $0.56 \%$ & $0.97 \%$ & $1.870 \%$ & $333.92 \%$ \\
\hline & $\begin{array}{l}\text { seis } \\
\text { meses }\end{array}$ & $0.68 \%$ & $1.65 \%$ & $2.260 \%$ & $209.77 \%$ \\
\hline \multirow{2}{*}{ Bonos } & 3 años & $2.10 \%$ & $3.39 \%$ & Sin subasta & $61.43 \%$ \\
\hline & 10 años & $4.20 \%$ & $4.91 \%$ & Sin subasta & $19.20 \%$ \\
\hline
\end{tabular}

Fuente: elaboración propia con datos del Banco de España.

Este tipo de medidas pro-cíclicas no van a conseguir el objetivo buscado de "calmar" a los mercados, pues incluso entre analistas simpatizantes con este tipo de ajustes fiscales, se reconoce que estas acciones van a desacelerar aún más la economía. Desde junio hasta noviembre de 2010, la deuda soberana española ha pagado, de media, casi el doble de los tipos de interés que pagaba antes de "calmar" a los mercados. Aún más, coincidiendo con el momento álgido de la crisis irlandesa, en la subasta del 23 de noviembre, los 3500 millones de $€$ que se negociaron fueron entre tres y cuatro veces más caros que los precios de antes de las "necesarias reformas". Sólo en 2010, se pagaron más de 900 millones de $€$ suplementarios debido a la especulación de la banca contra el Estado español. Pero lo más grave está por llegar. España en 2011 debe renovar deuda por casi 90000 millones de euros. De ahí la urgencia de aplicar soluciones diferentes que frenen esta sangría.

La ayuda de la UE y del FMI es un préstamo a los Estados para que paguen sus deudas a aquellos bancos. "La supuesta ayuda del Fondo Monetario Internacional y de la Unión Europea a los países periféricos es una ayuda a los bancos del centro (de Alemania y Francia)" (Stiglitz, 2010: 105).

El Cuadro 5 muestra algunos datos fundamentales de la economía española durante el periodo 2000-2007. Al iniciarse la crisis, la deuda pública española era una de las más bajas de la UE-1 5 . Y la situación era incluso mejor cuando se analiza la evolución de la deuda pública neta, es decir, la que excluye la deuda propiedad del Estado. Ésta suponía sólo un 26.5\% del PIB en 2007. La deuda pública española tuvo un excelente comportamiento, descendiendo desde 
un 59.3\% del piв a un 36.2\%, descenso que se debió principalmente al elevado crecimiento económico del periodo. Asimismo, el déficit del Estado bajó también, alcanzándose un superávit en los años 2005, 2006 y 2007.

Cuadro 5: España. Indicadores económicos seleccionados

\begin{tabular}{|c|c|c|c|c|c|c|c|c|c|c|}
\hline & 2000 & 2001 & 2002 & 2003 & 2004 & 2005 & 2006 & 2007 & 2008 & 2009 \\
\hline Deuda bruta/PIB & 59.3 & 55.5 & 52.5 & 48.7 & 46.2 & 43 & 39.6 & 36.2 & 39.7 & 53.2 \\
\hline Deuda neta/PIB & - & - & - & - & - & 34.7 & 30.5 & 26.5 & 30.3 & 45.8 \\
\hline Pagos de interés & 3.2 & 3 & 2.7 & 2.4 & 2 & 1.8 & 1.6 & 1.6 & 1.8 & 1.6 \\
\hline $\begin{array}{l}\text { Saldo del gob. } \\
\text { general }\end{array}$ & -1 & -0.6 & -0.5 & -0.2 & -0.3 & 1 & 2 & 1.9 & -4.1 & -11.2 \\
\hline $\begin{array}{l}\text { Saldo primario del } \\
\text { gob. general }\end{array}$ & 2.2 & 2.4 & 2.2 & 2.1 & 1.7 & 2.8 & 3.7 & 3.5 & -2.5 & -9.4 \\
\hline $\begin{array}{l}\text { Crecimiento PIB } \\
\text { real (variación } \\
\text { en \%) }\end{array}$ & 5.1 & 3.6 & 2.7 & 3.1 & 3.3 & 3.6 & 4 & 3.6 & 0.9 & -3.6 \\
\hline
\end{tabular}

Fuente: Weisbrot y Montecino, 2010.

Hay que tener en cuenta que la deuda pública española, incluso ahora, no es exagerada. En realidad, las necesidades de financiación en 2010 -la exposición a los "mercados" - han representado 65000 millones de euros y se estima que serán cerca de 90000 millones de euros en 2011. Esta cantidad es una cantidad menor comparada con los 750000 millones de euros que la UE y el FMI tienen disponible para ayudar a los Estados miembros de la UE en dificultades financieras. De ahí que si las autoridades de la UE y del FMI desearan evitar el crecimiento de los intereses de la deuda pública soberana española, lo podrían hacer fácilmente, poniendo aquel dinero a disposición de España, al tipo de interés de referencia del BCE, que es el 1\%. De este modo, se aseguraría a los "mercados financieros" que España podría pagar su deuda sin más dolores de cabeza, y se acabaría el negocio de la especulación y el "saqueo" de las arcas públicas españolas. 


\section{EL COMPORTAMIENTO DEL SECTOR FINANCIERO DURANTE LA CRISIS}

Las reformas permisivas por parte del BCE y FMI respecto a los criterios contables, permite que los activos tóxicos, hipotecas basura, créditos incobrables, y para el caso concreto de España, pisos adjudicados en subastas, se valoren a los precios de tasación anteriores a la crisis y no los reales de mercado actual. Los balances de los bancos españoles no reflejan ni mucho menos su valor real actual sino una ficción que las autoridades pretenden ir disolviendo con el tiempo.

Mientras cierran miles de empresas por falta de financiación y el desempleo no deja de aumentar, el Banco de España puso directamente a disposición de los bancos más de 230000 millones de euros, una cantidad que representa el $20 \%$ del PIв y más del doble de lo que el Estado se gasta en pensiones cada año (Navarro, 2010c). Gracias a ello, los beneficios de los bancos han seguido siendo multimillonarios como se puede ver en el Cuadro 6.

Cuadro 6: Los beneficios de la banca española en los últimos ejercicios

\begin{tabular}{llll}
\hline & 2008 & 2009 & 2010 \\
\hline provisiones y dotaciones & 17134 & 26792 & 22909 \\
dividendos & 9849 & 6905 & 6110 \\
capitalización de resultados & 10853 & 8254 & 7145 \\
\hline
\end{tabular}

Fuente: Elaboración propia con datos de la Asociación Española de Banca. http://www.aebanca.es/internet/groups/public/documents/presentaciones/01-201101373.pdf

Estas cantidades fabulosas se conjugan, sin embargo, con la pérdida de empleo en el sector, con los problemas de solvencia y, sobre todo, con la falta de liquidez y de financiación que padece la economía. Los bancos españoles no dedican este dinero a proporcionar créditos a los sujetos económicos, sino a colocarlos en deuda, en inversiones especulativas o simplemente en depósitos en los propios bancos centrales que proporcionan intereses más elevados. ${ }^{19}$

19 El pasado julio, Ana Patricia Botín, entonces presidenta de Banesto, ante la pregunta de porqué Banesto acudía al rescate ofrecido por el Banco de España, si las cifras expuestas mostraban a un banco saneado y con beneficios crecientes, simplemente contestó: "Es un buen negocio". 
Mientras tanto, los escasos particulares y empresas españolas que consiguen los parabienes de la banca para obtener financiación, deben pagar el dinero a precios escandalosos.

Cuadro 7: Tipos de interés en España

(diciembre 2010)

\begin{tabular}{ccccc}
\hline $\begin{array}{c}\text { Tipo referencia } \\
B C E\end{array}$ & Euribor & $\begin{array}{c}\text { Tipo interés legal } \\
\text { España }\end{array}$ & Tipo Hipotecario & Tipo Consumo \\
\hline $1 \%$ & 1.23 & $4 \%$ & $5.12 \%$ & $9.33 \%$ \\
\hline
\end{tabular}

Fuentes: BCE y Banco de España. Para préstamos hipotecarios y al consumo, se trata de tipos medios.

A pesar del gran negocio que, aparentemente, supone prestar dinero hoy en día, la banca sigue sin ejercer esta función. El Cuadro 8 muestra cómo la tendencia de los bancos en la eurozona a no prestar se encuentra altamente generalizada y amparada por el вСE y el FMI. Según el вCE, el 43\% de las entidades bancarias europeas habían restringido el crédito en el primer trimestre de 2009 a sociedades; el $28.7 \%$ el hipotecario y el 30\% el destinado al consumo. Para el caso de España, los porcentajes fueron del 40\%, 30\% y 40\% respectivamente. Asimismo, el 62.4\% de las entidades habían aplicado márgenes más elevados al crédito a sociedades, el $47.2 \%$ al hipotecario y el $44 \%$ al del consumo.

Cuadro 8: Disminución en la concesión de créditos 2009-2008

\begin{tabular}{|c|c|c|c|}
\hline Disminución de concesión de créditos 2009 / 2008 (\%) & Sociedades & Hipotecario & Consumo \\
\hline España & $40 \%$ & $30 \%$ & $40 \%$ \\
\hline Unión Europea & $43 \%$ & $28.7 \%$ & $30 \%$ \\
\hline
\end{tabular}

Fuentes: BCE y Banco de España.

El Banco de Espańa, aprovechando la crisis, promueve la concentración del sector bancario promulgando nuevas leyes de reordenación del sector encaminadas a la progresiva privatización de las cajas de ahorros, para que la banca privada se quede poco a poco con el importante segmento de mercado que está ocupando. Estas medidas sólo van a beneficiar a los grandes grupos de inversores 
mundiales, ya que no va a suponer una mayor eficiencia en el mercado financiero español, sino más escasez de créditos, dinero más caro y, además, mucha menor capacidad para que la ciudadanía y los poderes públicos puedan decidir las líneas de desarrollo futuras de la economía.

Como bien ha dicho Joseph Stiglitz, "con todos los fondos gastados para ayudar a los banqueros y accionistas se podrían haber creado bancos públicos que ya habrían resuelto los problemas de crédito que estamos experimentando" (Stiglitz, 2010: 82).

\section{CONCLUSIÓN}

Las raíces de esta crisis son muy profundas y se encuentran en la esencia misma de las economías capitalistas. El volcán que estalló en 2008 es la parte visible de un desastre que se cocina desde hace más de 30 años. Los orígenes se encuentran en la compresión salarial que a partir de los años 70 provocó que el crecimiento se redujera, la masa salarial cayera y la desigualdad aumentara.

La actuación incompleta frente a la crisis está provocando gravísimas secuelas. Desde el principio se hizo hincapié en los estímulos a la economía, en reducir las pérdidas de empleos y en el sostén a los estratos más débiles. Así se logró impedir otra Gran Depresión a costa de ahondar los déficits públicos, pero se cometió el error de salvar los bancos a la deriva sin reformar el sistema financiero disfuncional que había desencadenado la crisis. La reacción de los mercados financieros a la elevación del endeudamiento público ha hecho volver al mundo al rumbo tradicional de una economía política de libre mercado, saneamiento de la hacienda pública, adelgazamiento del Estado y retroceso de la protección social. Ahora acechan dos peligros: el incremento de la desigualdad y la inestabilidad económica.

Durante 2008, en varias Cumbres del G-20, los dirigentes de los Estados más poderosos decidían terminar con los paraísos fiscales, controlar los fondos de alto riesgo (Hedge Funds) y sancionar los abusos de los especuladores causantes de la crisis. José Manuel Durão Barroso, Presidente de la Comisión Europea, declaraba: "Las autoridades políticas no toleraremos nunca más que los especuladores vuelvan a levantar cabeza y nos arrastren a la situación anterior" ${ }^{20}$

Y sin embargo, no sólo hemos vuelto a la situación anterior sino que de nuevo, los mercados y los especuladores tienen la sartén por el mango. Los

20 José Manuel Durão Barroso, citado por Ignacio Ramonet, 2010, "Neoliberalismo obligatorio", www.simpermiso.com 
"mercados", apoyados por las agencias de calificación, atacan a los Estados periféricos de la UE, altamente endeudados y acusados ahora de vivir por encima de sus posibilidades. La política de la disciplina fiscal, de la reducción del déficit, la deuda, el tamaño del gobierno y del sector público, que nos gobernó antes de la crisis, se esgrime ahora como programa para salir de ella. Se trata, en definitiva, de reducir el Estado de bienestar, recortar los derechos laborales, debilitar a los sindicatos, reducir los salarios y aumentar la explotación para, en definitiva, incrementar los beneficios de las clases empresariales.

En Europa, el BCE y el FMI, alentados principalmente por la banca, actúan como centros de poder externos a la región. Toman decisiones que los Estados periféricos de la Unión deben acatar en sus estrategias y programas de gobierno. Para el caso de España, este panorama es desolador. El colapso de nuestra economía con más de un $20 \%$ de parados y una débil demanda interna, precisan de un estímulo económico que sólo el Estado puede ofrecer. Sin embargo, las imposiciones del BCE y FMI caminan en la dirección contraria; se nos exige que disminuyamos la deuda y reduzcamos el gasto público, excepto para el pago de los intereses de la deuda.

La magnitud alcanzada por el empleo atípico en España ha provocado el descenso de los salarios, y con él, la caída de la demanda privada. La solución no puede ser abaratar el despido, incrementar la inseguridad económica y seguir disminuyendo los salarios. Para salir de la crisis es necesario que el aumento de los salarios reales vaya al compás de los incrementos de la productividad. Este aspecto es clave para mantener la demanda interna sin necesidad de apuntalar el consumo por medio de deuda privada o de ayudas estatales en favor de los estratos sociales más débiles.

Esta crisis es la historia del fracaso de un modelo ultraliberal en el que la receta que se nos quiere imponer es profundizar en el error. Las élites económicas nacionales y globales no deberían sorprenderse de que la opinión pública reaccione con una mezcla de cólera e incomprensión no sólo hacia los bancos, sino hacia todo el sistema político que los alimenta a costa de enormes sacrificios para las clases populares que no tuvieron ninguna responsabilidad en esta crisis.

\section{BIBLIOGRAFÍA}

Asociación Española de Banca (AEB), 2010: al final, peor que al principio 2011: mejor al final, 30 de marzo, 2011.

Banco Central Europeo (вСЕ), Boletín marzo, 2010. 
Boletín Oficial del Estado. BоE, Real Decreto-Ley 8/2010, de 20 de mayo, por el que se adoptan medidas extraordinarias para la reducción del déficit público, 2010.

Comisiones Obreras, "Reformas Laborales", disponible en http://www.ccoo. cat/pdf_documents/REFORMAS\%20\%2OLABORALES.pdf 2010

Consejo General del Poder Judicial, Informe anual 2010.

Diario Cinco Días, La gravedad de las ejecuciones hipotecarias, 24/7/2010.

El pais, La FED ha inyectado 600.000 millones de USD a su economia, 3/11/2010.

Esteve V., Viaje al fondo de las finanzas internacionales,

Blogspot. http://vicenteesteve.blogspot.com/. 2010.

Eurostat, Diferentes informes.

Fondo Monetario Internacional (FMI), Perspectivas de la economía mundial. Reequilibrar el crecimiento, Washington, abril 2010.

, Perspectivas de la economía mundial. Sustentar la recuperación, Washington, octubre 2009.

Instituto Internacional de Estudios Laborales de la OIT, (IIEL), Informe sobre el trabajo en el mundo 2009. Crisis mundial del empleo y perspectivas, Ginebra, 2009.

Instituto Nacional de Estadística (INE), diferentes informes.

Krugman, Paul, The Return of Depression Economics and the Crisis of 2008, Allen Lane, Londres, 2009.

Magdoff, F. y Yates, M., The ABCs of the Economic Crisis: What Working People Need to Know, Monthly Review Press, Nueva York, 2009.

Marqués Corral José Manuel, Luis Ángel Maza y Margarita Rubio, Una comparación de los ciclos inmobiliarios recientes en España, Estados Unidos y Reino Unido, Banco de España, Boletín Económico, enero 2010, pp. 107-118.

Minsky, Hyman Philip, Global Consequences of Financial Deregulation, Washington University, Department of Economics, Working Paper Series, No 96, September, 1986.

Moreno Fernando, Javier Molina y Manauel Luque, Productividad y relaciones laborales. Estudio sobre la regulación del tiempo de trabajo. Absentismo. Temporalidady su repercusión sobre la productividad, CEv, Valencia, 2010.

Navarro, Vicens, Gasto público y políticas sociales. ¿Qué papel juegan en la actualidad?, disponible en www.vnavarro.org, 2010a.

, ¿Por qué no banca pública?, en www.vnavarro.org, 2010b.

, El capital financiero y su supervisor (el Banco de España) son responsables del elevado desempleo, http://www.vnavarro.org/?p=5145. 2010c

Organización Internacional del Trabajo (огт), Informe sobre el trabajo en el mundo 2010: ¿De una crisis a la siguiente?, 2010.

Ramonet, Ignacio, Neoliberalismo obligatorio, www.simpermiso.com, 2010. 
Stiglitz, Joseph Eugene, Caída libre. El libre mercado y el hundimiento de la economia mundial, Taurus, Madrid, 2010.

The New York Times, Newly Built Ghost Towns Haunt Banks in Spain, 18/12/2010.

The New York Times, A Spanish Bailout Would Test Europes Strained Finances, 24/11/2010.

Torres López, Juan, Crisis inmobiliaria, crisis crediticia y recesión económica en España, Papeles de Europa, Vol. 19, 2009, pp. 82-107.

Ugarteche, O., Lecciones de la crisis de América Latina de los años 80 para la crisis de Europa de hoy, Rebelión, disponible en http://www.rebelion.org/noticia. php?id=119538. 02-01-2011.

Weisbrot, Mark, El mito de la recuperación alemana, www.sinpermiso.com, 2010.

Weisbrot, Mark y otros, IMF Supported Macroeconomic Policies and the World Recession: A Look at Forty? One Borrowing Countries, Center for Economic and Policy Research, www.cepr.net/documents/publications/imf-2009-10. pdf, 2009.

Weisbrot, Mark y J. Montecino, Alternativas a la austeridad fiscal en España, Center for Economic and Policy Research. www.cepr.net/documents/publications/spain-2010-07-sp.pdf, 2010. 